\title{
SHOULD WE SWAP INTERNAL FOUNDATIONS FOR VIRTUES?
}

\author{
RAM NETA \\ Department of Philosophy \\ University of North Carolina, Chapel Hill \\ neta@email.unc.edu
}

SUMMARY: Internalist foundationalism was popular through much of the history of Western epistemology, but has been subjected to intense critical scrutiny in the last century. Ernest Sosa's new book presents some novel and seemingly powerful arguments against internalist foundationalism. After laying out these arguments, I attempt to rebut them. I argue that Sosa does not, after all, give us good reason for abandoning internalist foundationalism.

KEY WORDS: foundationalism, internalism, reflection, Sosa

RESUMEN: El fundacionismo internista ha sido muy popular a lo largo de la historia de la epistemología occidental, pero en el último siglo ha sido sometido a un intenso escrutinio crítico. En A Virtue Epistemology, vol. I, Ernesto Sosa presenta algunos argumentos novedosos y aparentemente poderosos contra el fundacionismo internista. Después de presentar estos argumentos, intento rebatirlos. Mi argumento es que Sosa, después de todo, no nos ofrece una buena razón para abandonar el fundacionismo internista.

PALABRAS CLAVE: fundacionismo, internismo, reflexión, Sosa

A normal human adult possesses the capacity to discern the reasons that she has for believing or intending things, to evaluate whether those reasons are good reasons for having the beliefs or intentions that she has, and to revise her beliefs or intentions in response to that evaluation. Let us call this the capacity for "critical reasoning". Since any of our beliefs, experiences, desires, or intentions can supply reasons for us to believe or intend things, the capacity for critical reasoning includes our capacity to discern what beliefs, experiences, desires, or intentions we have. And since the evaluation of reasoning itself requires reasoning, the capacity for critical reasoning includes our capacity to reason, and to discover truths purely by means of reasoning. Thus, the capacity for critical reasoning gives us access to (at least some of) our own mental states, and it also gives us access to the truths of reason. It doesn't give us access to just anything though: for instance, it doesn't give us access to the date of Abraham Lincoln's birth, the atomic number of gold, or the solution to the current financial crisis. Critical reasoning gives 
a person access to all and only those facts that jointly determine what that person rationally ought to believe or intend. We'll sometimes put this point by saying that it is all and only these facts that are "reflectively accessible" or that all and only these facts can be known "by reflection alone".

A believer's failure to believe any one of these facts constitutes a failure to exercise fully her powers of critical reasoning. Of course, a believer might be perfectly blameless in this failure. In fact, a believer might have compelling reasons to fail to exercise fully powers of critical reasoning: maybe fully exercising her powers of critical reasoning is bad for her health (everything in moderation). Still, failure to believe such a fact can constitute a rational failing of a particular, epistemic kind. And so it is sometimes thought that the mere obtaining of one of these facts makes it in some epistemic respect rational for a person to believe that that fact obtains. We can make the same point using the epistemologist's term "justification": the mere obtaining of one of these facts gives us justification for believing that that fact obtains.

To say that normal human adults possess the capacity for critical reasoning is not to say that the capacity is well-developed or competently exercised in each of us at all times: passions, drugs, and illness can hinder the development of this capacity in individual humans, and these factors can also hinder the exercise of this capacity even when it is developed. But, even if the capacity is never perfectly developed, and seldom competently exercised, it is nonetheless a capacity that normal human adults possess in some measure. Indeed, its possession by a particular human is part of what makes that human a normal adult.

According to a historically influential Cartesian picture of knowledge, all of the knowledge that normal human adults possess is knowledge that is, in one or another way, built out of the epistemic deliverances of critical reasoning -i.e., it is built out of our knowledge of just those facts that determine what we rationally ought to believe or intend. According to an especially prominent foundationalist version of this picture, our empirical beliefs about the world around us are justified by our knowledge of our own sensory experiences and apparent memories: critical reasoning tells us what experiences and apparent memories we're having, and it also tells us what justificatory relations obtain between our knowledge of those experiences and memories, on the one hand, and our beliefs about the world around us, on the other. This is a view that was 
accepted by Bertrand Russell, ${ }^{1}$ G.E. Moore, ${ }^{2}$ Roderick Chisholm, ${ }^{3}$ and many other English-speaking epistemologists throughout (and especially in the first two-thirds of) the twentieth century. ${ }^{4}$

Still, the view has not been universally accepted. Wilfrid Sellars, ${ }^{5}$ Keith Lehrer, ${ }^{6}$ Richard Rorty ${ }^{7}$ Donald Davidson, ${ }^{8}$ and Laurence BonJour $^{9}$ have all issued important challenges to it. But no one has done more than Ernest Sosa to cast doubt on this internalist foundationalist picture in epistemology, both as it applies to a posteriori knowledge and as it applies to a priori knowledge. Sosa has attempted to supplant the internalist, foundationalist picture with his own virtue-theoretic picture, which is neither fully internalist nor fully foundationalist (though it contains elements of each). Below, I will articulate two of his main challenges to the internalist, foundationalist picture, and then I reply to each of these two challenges on behalf of the internalist foundationalist. In section 1, I'll describe, and respond to, Sosa's challenge to the internalist, foundationalist picture of a priori knowledge, and then in section 2, I'll describe, and respond to, his challenge to the internalist, foundationalist picture of a posteriori knowledge. In section 3, I will address Sosa's Sellarsian worry that internalist foundationalism cannot offer a satisfactory solution to the Pyrrhonian problematic. And finally, in section 4, I will argue that the internalist foundationalist picture of knowledge offers explanatory resources that Sosa's virtue-theoretic picture does not offer.

\section{Sosa's Challenge to the Internalist, Foundationalist Picture of A Priori Knowledge}

What's wrong with the internalist, foundationalist picture of a priori knowledge, and why should we prefer Sosa's virtue-theoretic alternative to it? In his 2007 book, Sosa argues that internalist foundationalism cannot account for the role that our intuitions play in providing us with a priori knowledge.

${ }^{1}$ See Russell 1912.

${ }^{2}$ See Moore 1962.

${ }^{3}$ See Chisholm 1989.

${ }^{4}$ A recent, prominent instance of such a defender of internalist foundationalism is Laurence BonJour. See his contribution to BonJour and Sosa 2003.

${ }^{5}$ See Sellars 1956.

${ }^{6}$ See Lehrer 2000.

${ }^{7}$ See Rorty 1979.

${ }^{8}$ See Davidson 1983.

${ }^{9}$ See BonJour 1985. 
According to an internalist foundationalist, what role do intuitions play in giving us a priori knowledge? Such intuitions must somehow stop the regress of a priori justifications, and the only way that they can do this is by providing a priori justification without requiring it themselves (i.e., without themselves being evaluable as justified or unjustified). So a foundationally justified a priori belief, like $0<1$, must be justified by an intuition, which is something distinct from the belief, and accessible to reflection, and not itself evaluable with respect to justification. But, Sosa thinks, there simply is no such thing: there is nothing distinct from my belief that $0<1$, that is accessible to reflection, and that both justifies that belief and is itself not evaluable with respect to justification. What justifies my belief that $0<1$ is my attraction to that belief, but this attraction can be justified or unjustified: I may be justifiably attracted to the belief, or unjustifiably attracted to it. Since the attraction is itself evaluable with respect to justification, it cannot stop the regress of justification. Since the thing that justifies my a priori belief is not a regress-stopper, the internalist foundationalist cannot account for such a priori knowledge.

Can the internalist solve this problem by rejecting foundationalism, and accepting some form of coherentism or infinitism instead? No. For according to Sosa, what justifies my attraction to the belief that $0<1$ is not any other belief or experience of mine; what could that belief or experience possibly be?! The only plausible account of what justifies my attraction to the belief that $0<1$ is that this attraction is a proper exercise of my epistemic competence. And since, for Sosa, this fact about the attraction is not a fact that is accessible to introspection or reflection, it is not a fact that the internalist can admit into her account of what justifies my belief. Thus, internalism cannot give an adequate account of our a priori knowledge. Since internalism cannot give an adequate account of our a priori knowledge, it also cannot give an adequate account of our knowledge of epistemological principles, and so cannot explain how we can achieve a knowledgeable perspective on our own knowledge. And without being able to explain this, internalism cannot provide us with a way to solve the problem(s) of the criterion.

So to sum up: Sosa argues that internalist foundationalism cannot offer an adequate account of our a priori knowledge, because there are no mental states that can serve to stop the regress of a priori justification (or, at least, there are no mental states accessible to the believer's own powers of reflection that can do so). The only thing that justifies my belief that, say, $0<1$, is my justified attraction to 
that belief, and the only thing that justifies that attraction is the fact (allegedly inaccessible to my reflection) that it consists in the proper exercise of a competence.

Now, could the very fact that $0<1$, a fact that is accessible to me upon reflection, be what justifies my belief that $0<1$ ? Sosa argues that, if we claim that the very fact that $0<1$ is what justifies my belief that $0<1$, then we will have to explain why that fact justifies my belief in it, whereas the fact (supposing it is a fact) that the axiom of choice is true does not justify my belief in it. If both facts are, in principle, epistemically accessible upon reflection, then why is it that only the first is actually accessed by me (even if, as it happens, I believe both)? Sosa thinks that, in order to answer this question, we must appeal to the fact that I properly exercise my powers of reflective knowledge in believing the first fact, but not in believing the second. Let's grant that he is right to say this. Still, this is inconsistent with internalism only if the fact that I properly exercise my powers of reflective knowledge in believing that $0<1$ is itself not accessible to my powers of reflection. But why should we think that this latter fact is not accessible to my powers of reflection?

Perhaps we should think that facts about whether I am properly exercising one of my epistemic powers are inaccessible to my powers of reflection because they are facts about the causal order. But consider the fact that my attention is now directed to a particular red spot in my visual field, and I am accurately tracking this single red spot as it moves across the field. This fact about the accuracy of my tracking is also a fact about the causal order, and yet it seems clearly to be accessible to me upon reflection. Why not allow that the fact that $\mathrm{I}$ am accurately reflecting upon the fact that $0<1$ is also accessible to me upon reflection?

Perhaps we should think that facts about whether I am properly exercising one of my epistemic powers are themselves inaccessible to my powers of reflection because they metaphysically entail facts that are not themselves reflectively accessible. For instance, the fact that I am properly exercising my powers of reflective knowledge in believing that $0<1$ metaphysically entails that there is no psychosis-inducing gas in the air that I'm now breathing. But I certainly cannot know by reflection alone that there is no such gas in the air I'm breathing. So can reflection alone enable me to know something that entails this? Yes. Even if we accept that knowledge is closed under known entailment, we need not accept that knowledge by reflection alone is closed under known entailment. If I know that 
I'm properly exercising my powers of reflective knowledge in believing that $0<1$, and I know that this is possible only if there is no psychosis-inducing gas in the air that I'm breathing, then (let's grant) it follows that I know that there is no psychosis-inducing gas in the air that I'm breathing. But it doesn't follow that I must know this by reflection alone. Perhaps it is possible for me to know some things by reflection alone only if I know other things in some other, nonreflective way.

Of course, to allow that I can know by reflection alone that I'm properly exercising my powers of reflective knowledge in believing that $0<1$ is not to imply that we are not subject to error in our beliefs about our own reflective powers. It might frequently happen that we falsely believe that we are properly exercising our powers of reflection when, in fact, we are not doing so. Furthermore, when we are improperly exercising our powers of reflection, that fact may be inaccessible to us. But none of this implies that when we are properly exercising our powers of reflection, that fact is not accessible to us. So what reason is there to think that, when we are properly exercising our powers of reflection in reflecting upon some fact, the very fact that we are doing so is not itself accessible to our own powers of reflection? In order for Sosa to make his case against the internalist foundationalist picture of a priori knowledge, and to show that some appeal to virtue is necessary for an adequate account of such knowledge, he must provide an answer to this question. So far as I can see, he does not do so anywhere in his 2007 book.

But perhaps the answer to this question is to be found, explicitly or implicitly, in the work that Sosa has done to criticize the internalist foundationalist picture of a posteriori knowledge. Let's now turn to that work, to see whether we can find there the resources to complete Sosa's critique of internalist foundationalism.

\section{Sosa's Challenge to the Internalist, Foundationalist Picture of A Posteriori Knowledge}

What's wrong with the internalist, foundationalist picture of a posteriori knowledge, and why should we prefer Sosa's virtue-theoretic alternative to it? Sosa's most fully developed criticism of the internalist, foundationalist picture of a posteriori knowledge is offered in his contribution to BonJour and Sosa 2003. There, he argues that internalist foundationalism cannot account for the role that perceptual experience plays in giving us a posteriori knowledge of the world. 
According to an internalist foundationalist, what role do perceptual experiences play in giving us a posteriori knowledge? Such experiences must somehow stop the regress of a posteriori justifications, and the only way that they can do this is by providing a posteriori justification without requiring it themselves (i.e., without themselves being evaluable as justified or unjustified). So a foundationally justified a posteriori belief, like the belief that it appears to me as if there is something white in front of me, must be justified by my perceptual experiences, which are distinct from the belief, and accessible to reflection, and not themselves evaluable with respect to justification.

Just as Sosa denies that anything can play the role of a reflectively accessible regress-stopper with respect to our a priori justifications, so too does he deny that anything can play the role of a reflectively accessible regress-stopper with respect to our a posteriori justifications. Why does he think that perceptual experiences cannot play this role? Sosa might grant that perceptual experiences have two of the characteristics of reflectively accessible regress-stoppers: they are reflectively accessible, and they cannot themselves be either justified or unjustified. But do they have the remaining characteristic? Can they, by themselves, justify beliefs? To see why Sosa thinks that they cannot do so, consider the visual experience that you have when you look at a well lit many-speckled hen a few feet in front of you. Suppose that the hen has 48 speckles in your visual field, and so your visual experience of the hen consists of a visual array containing 48 speckles. Now, even though you might figure out that your visual array contains 48 speckles by attending to those speckles and carefully counting them, unless you perform these acts of attention and counting, you will not know that your visual array contains 48 speckles. Nonetheless, suppose that, although you don't attend to the speckles or count them, you just happen to believe (for whatever bad reason) that your visual array contain 48 speckles. In this case, even though your visual array does contain 48 speckles, your belief that it contains 48 speckles is unjustified. So, your visual experience does not, by itself, justify your belief that the visual array contains 48 speckles.

Should we say that, even if the experience does not, by itself, justify your belief that the visual array contains 48 speckles, still, your experience, in tandem with your attention to each speckle, and your counting the speckles, does justify your belief that the visual array contains 48 speckles? Suppose that your experience presents to you an array containing 48 speckles, you attend to each 
speckle, and you count the speckles. Does it then follow that your belief that the visual array contains 48 speckles is justified? No. You could have the experience, attend to each speckle, count the speckles, and then simply ignore the results of your counting and proceed to believe (for whatever bad reason) that your visual array contains 48 speckles. Once again, your belief is true, but it is not justified. So your experience, attention, and counting, all in tandem, do not suffice to justify your belief that your visual array contains 48 speckles.

In order for that belief to be justified, it must result in the right way from your experiencing, attending to, and counting, the speckles. So what stops the regress of a posteriori justifications in this case is not your visual experience; rather it is the way that you form your beliefs on the basis of that visual experience. In general, Sosa concludes, what stops the regress is not - as the internalist, foundationalist would have it - a reflectively accessible mental state or event (e.g., belief, experience) but rather the proper exercise of a cognitive competence.

But now the internalist foundationalist can raise the same sort of question here that she raised above, in response to Sosa's arguments concerning intuitions. Consider the fact that

(F) your belief that there are 48 speckles in your visual array results in the right way from your counting the 48 speckles in your visual array.

Why can't $\mathrm{F}$ itself be accessible to reflection? And if $\mathrm{F}$ is accessible to reflection, then haven't we found the reflectively accessible regressstopper that we were looking for, namely, F (or, if you prefer, the causal relation mentioned in our statement of F)? To complete his critique of internalist foundationalism, Sosa would have to tell us why the fact $\mathrm{F}$ (or the causal relation that we've mentioned in our statement of $\mathrm{F}$ ) is not reflectively accessible. But, so far as I can see, this is not something that he does.

Maybe Sosa does not do this because he thinks that, even if $\mathrm{F}$ is reflectively accessible, its being so cannot be of any use to the foundationalist. In his discussion of the Pyrrhonian problematic, Sosa sympathetically discusses the Sellarsian critique of internalist foundationalism. Perhaps his most serious objection to internalist foundationalism is to be found in that discussion, and so it is that discussion to which we turn now. 


\section{Sosa's Challenge to the Internalist, Foundationalist Solution to the Pyrrhonian Problem}

In lecture 6 of his 2007 book, Sosa locates what he takes to be an insight in Sellars's critique of internalist foundationalism concerning a posteriori knowledge: "In order to be fully justified, perceptual belief requires background beliefs (assumptions) that in turn require justification" (Sosa 2007, p. 124). If this is right, then perceptual beliefs cannot be fully justified solely on the basis of things that are not beliefs (e.g., experiences). The justification of perceptual beliefs depends at least in part upon the justification of other beliefs. But, as coherentists such as BonJour, Lehrer, Rorty, and Davidson have all said, the point that Sellars makes about perceptual beliefs applies to all beliefs:

(Circle) No belief can be fully justified except by appeal to other justified beliefs.

I take it that Sosa's most general challenge to internalist foundationalism consists of an appeal to the plausibility of Circle.

Now, it is important to note an ambiguity in Circle. Does the terminal occurrence of the word "beliefs" in Circle being used to refer to belief states of the believer, or is it being used to refer to things that the believer believes? I see no reason to accept the former reading: nothing that Sellars or any of the other coherentists say provides a good reason for believing Circle if the first reading of "beliefs" is the correct one. The second reading, however, makes Circle quite plausible: for any particular fully justified belief $\mathrm{B}$, whatever it is that justifies $\mathrm{B}$ must be something $\mathrm{S}$ that the believer is justified in believing to obtain. Furthermore, the believer must be justified in believing that the obtaining of $\mathrm{S}$ makes $\mathrm{B}$ likely to be true. If $\mathrm{B}$ is justified by some perceptual episode, say, then the believer must be justified in believing that that episode occurs, and must also be justified in believing that the occurrence of that episode makes it likely that B is true. If B is justified by some reasoning, then the believer must be justified in believing that she has done that reasoning, and must also be justified in believing that that reasoning makes it likely that B is true. And so on.

If Circle, on this second interpretation, is true, then does this pose a problem for internalist foundationalism? It may seem to do so, because Circle, so interpreted, may seem to be incompatible with the claim that there are regress-stoppers. But, as I'll now argue, this appearance is misleading. Suppose that there are 
regress-stoppers, e.g., perceptual experiences, or intuitions. Circle tells us that, whatever these regress-stoppers are, in order for any beliefs that are justified on the basis of those regress-stoppers to be fully justified, the believer must be justified in believing that those regress-stoppers obtain, and must also be justified in believing that those regress-stoppers make the belief in question likely to be true. What can justify the believer in believing each of these two latter things?

If the regress-stoppers are reflectively accessible (as the internalist foundationalist requires them to be), then the regress-stoppers can themselves give the believer justification for believing that those very same regress-stoppers obtain: recall that, when we have reflective access to some fact, then that very fact suffices for us to be justified in believing that fact. And so, just as the believer is justified in holding various beliefs on the basis of those regress-stoppers, the believer is also justified in believing that those regress-stoppers obtain, and she is justified in believing this on the basis of the obtaining of those very same regress-stoppers. But what justifies the belief that the occurrence of those regress-stoppers renders the belief to be justified on the basis of those regress-stoppers likely to be true? According to the internalist foundationalist, the principles that determine how justification is distributed over beliefs, given a particular totality of regress-stoppers, are themselves reflectively accessible. ${ }^{10}$ Just as reflection gives us access to which regress-stoppers obtain, so too does it give us access to the principles that determine, for any given body of regress-stoppers, which beliefs are justified on the basis of those regress-stoppers. But recall that, when we have reflective access to some principle, then the very truth of that principle suffices for us to be justified in believing that principle. So, just as the obtaining of a particular regress-stopper justifies us in believing that that regressstopper obtains, so too does the truth of particular principles determining how justification is distributed over beliefs, given a particular totality of regress-stoppers, give us justification for believing those same principles.

10 "The internalist assumes that merely by reflecting upon his own conscious state, he can formulate a set of epistemic principles that will enable him to find out, with respect to any possible belief he has, whether he is justified in having that belief. The epistemic principles that he formulates are principles that one may come upon and apply merely by sitting in one's armchair, so to speak, and without calling for any outside assistance. In a word, one need consider only one's own state of mind" (Chisholm 1989, p. 77). 
So, whenever particular regress-stoppers obtain in the mental life of a particular believer, and particular principles of justification are correct, that believer will be justified in believing that those regress-stoppers obtain, and that those principles are true. Couldn't a believer be justified in believing these things, but still fail to believe them? Of course she could, but notice that, if she failed to believe these things, that would be a rational failing on her part. How does this rational failing affect the degree to which the believer's beliefs are justified? For some of those beliefs, it might not affect their degree of justification at all. For instance, the degree of justification enjoyed by the believer's belief that (say) Abraham Lincoln was born on a Sunday might be completely unaffected by the believer's failure to believe that certain regress-stoppers obtain, or that certain principles of justification are true. But, to the extent that a particular belief's justification depends precisely upon the obtaining of those regress-stoppers, or the truth of those principles of justification, the believer's failure to believe that those regressstoppers obtain, or to believe that those principles are true, will negatively affect the degree of justification enjoyed by that particular belief.

If this is correct, then internalist foundationalism is compatible with Circle. In fact, not only is internalist foundationalism compatible with Circle, but, in conjunction with the plausible claim that the extent of a belief's justification in believing that $p$ is negatively affected by a believer's failure to believe things that it is rational for her to believe, concerning the justificatory basis for her belief that $p$, internalist foundationalism actually entails Circle!

This completes my defense of internalist foundationalism against Sosa's challenges to it. In the remaining section of this paper, I will attempt to show that we have some positive reason to prefer internalist foundationalism to Sosa's virtue-theoretic alternative.

\section{The Explanatory Advantages of Internalist Foundationalism over Sosa's Account of Knowledge}

On Sosa's view, to have animal knowledge that $p$ is to believe that $p$, and for this belief to be apt -in other words, for it to be accurate (i.e., true) because adroit (i.e., skillfully formed). To have reflective knowledge that $p$ is to aptly believe that you aptly believe that $p$ -in other words, for you to have a belief that is accurate because adroit that your belief that $p$ is accurate because adroit. 
One may suspect that both of these accounts are subject to counterexample. Suppose that I have a telekinetic mechanism in my brain, and it is coupled to an adroitness detector: call the coupled mechanism M. As I am about to adroitly tell the time by looking at a clock, M detects that I am about to do this, and so causes the clock to stop on the correct time: I look at the clock, form a true belief concerning the time, and my belief is true because I formed it adroitly, just as $\mathrm{M}$ detected that I was going to do. But my belief is not any kind of knowledge, even though it may seem that I satisfy Sosa's conditions on animal knowledge.

Now suppose that, because I have a coherent picture of my environment and the reliability of my epistemic competences in that environment, $M$ causes me to suffer veridical hallucinations: I continue to have veridical experiences as of my environment, and so continue to have true belief about my environment, but $\mathrm{M}$ generates these experiences itself, and thereby insures that these experiences are not properly connected to my environment. (In order for this story to be coherent, it is important to stipulate that, while I believe that my beliefs are coherent and reliably formed, I do not hold any beliefs about the mechanisms by which these beliefs were formed: I simply believe that these beliefs are reliably true.) Here, it may seem, my beliefs are true because adroitly formed, and my beliefs to the effect that my beliefs are true because adroitly formed are themselves true because adroitly formed. But I do not have reflective knowledge, because of my coherent beliefs are based on a complex web of hallucination.

Sosa has an obvious strategy for replying to both of these putative counterexamples: he will say that, in the cases described, the truth of my beliefs is to be explained not solely, or even primarily, by reference to my adroitness in forming them, but also by reference to the operation of the telekinetic mechanism in my brain. In short, he will claim that these examples do not satisfy his conditions on animal knowledge or on reflective knowledge. But this response raises a worry: why isn't the operation of the posited telekinetic mechanism simply part of the adroit exercise of the competence? Whatever else is involved in the adroit exercise of an epistemic competence, it will inevitably involve the operation of various mechanisms in the brain, and precisely which mechanisms operate in the exercise of that competence will be, to some extent, the result of evolutionary accident: the very same competence could have been implemented by means of different 
mechanisms, and it just so happens that, in our species, the competence is implemented by means of one rather than another set of mechanisms. Now, if the exercise of a competence inevitably involves the operation of various mechanisms (and could very well have involved the operation of different mechanisms, had evolution gone differently) then why can't the operation of some such telekinetic mechanisms as those posited in my stories above be one of the brain events involved in the adroit exercise of the epistemic competences at issue? Sosa would need to answer this question in order to give an adequate reply to the counterexamples offered above to his accounts of animal knowledge and of reflective knowledge. And I don't see what resources he has to answer them.

Now notice that the internalist foundationalist does not have any such problem, since the internalist foundationalist needn't appeal at any point in her theory to the notion of an epistemic competence. Of course, the internalist foundationalist who wants to offer an account of knowledge will have to offer one that is different from Sosa's (in order to avoid employing the concept of an epistemic competence), but, contrary to hearsay, the literature on that topic contains some promising candidates.

\section{REFERENCES}

Anscombe, G.E.M., 1957, Intention, Harvard University Press, Cambridge, Mass.

BonJour, L., 1985, The Structure of Empirical Knowledge, Harvard University Press, Cambridge, Mass.

BonJour, L., and E. Sosa, 2003, Epistemic Justification: Internalism vs. Externalism, Foundations vs. Virtues, Blackwell, Malden.

Chisholm, R., 1989, Theory of Knowledge, 3rd. ed., Prentice-Hall, Englewood Cliffs.

Davidson, D., 1983, “A Coherence Theory of Truth and Knowledge", in D. Heinrich (ed.), 1981, Kant oder Hegel?, Klett-Cotta Buehaudlang, Stuttgart, pp. 423-438.

Lehrer, K., 2000, Theory of Knowledge, Westview Press, Boulder.

Moore, G.E., 1962, "Four Forms of Scepticism", in Philosophical Papers, Collier Books, New York, pp. 196-225.

Rorty, R., 1979, Philosophy and the Mirror of Nature, Princeton University Press, Princeton.

Russell, B., 1912, The Problems of Philosophy, Oxford University Press, Oxford. 
Sellars, W., 1956, "Empiricism and the Philosophy of Mind", in H. Feigl and M. Scriven (eds.), Minnesota Studies in the Philosophy of Science, The Foundations of Science and the Concepts of Psychology and Psychoanalysis, vol. 1, University of Minnesota Press, Minneapolis, pp. 253-329.

Sosa, E., 2007, A Virtue Epistemology: Apt Belief and Reflective Knowledge, Volume I, Oxford University Press, Oxford.

Received: March 21, 2009; accepted: June 17, 2009. 